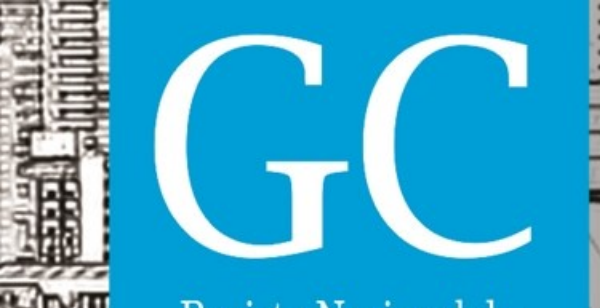

Revista Nacional de

\title{
Diagnóstico da implantação do plano municipal de gestão integrada de resíduos sólidos na região de Araçatuba
}

\author{
Deployment of diagnosis of municipal plan of integrated management of solid waste in \\ Araçatuba region
}

Despliegue de diagnóstico del plan municipal de gestión integrada de residuos sólidos en la región Araçatuba

\author{
Lucas Roberto Terneiro \\ Graduando, UNIP, Brasil. \\ lucasterneiro67@hotmail.com \\ Stéfani Tainá Belortti \\ Graduanda, UNIP, Brasil. \\ stefani_belortti@hotmail.com \\ Rafael Marçal \\ Professor Mestre, UNIP, Brasil \\ rafael_g1@hotmail.com
}




\title{
INTRODUÇÃO
}

Nas últimas décadas, tem-se observado grande preocupação da sociedade no que se refere a questões ambientais, sociais e políticas do meio em que se inserem. Destaca-se a sustentabilidade e o meio ambiente como assuntos relevantes, em que o tema do descarte de resíduos sólidos se sobressai nas esferas nacionais e internacionais.

A fim de evitar um colapso ambiental, foi criada em 2010 a Lei no 12.305/10 - Política Nacional de Resíduos Sólidos - PNRS, que é um dos principais instrumentos para permitir e possibilitar um avanço dos municípios e do país no que tange à gestão dos resíduos sólidos. A partir de então, os setores privados, o governo e a população começaram a ser responsáveis pelo gerenciamento adequado do descarte dos resíduos sólidos.

De acordo com a NBR 10004, resíduos sólidos são:

Resíduos nos estados sólido e semi-sólido, que resultam de atividades de origem industrial, doméstica, hospitalar, comercial, agrícola, de serviços e de varrição. Ficam incluídos nesta definição os lodos provenientes de sistemas de tratamento de água, aqueles gerados em equipamentos e instalações de controle de poluição, bem como determinados líquidos cujas particularidades tornem inviável o seu lançamento na rede pública de esgotos ou corpos de água, ou exijam para isso soluções técnicas e economicamente inviáveis em face à melhor tecnologia disponível (ABNT NBR 10004:2004).

A Lei Federal 12.305 de 02 de agosto de 2010, que institui a Política Nacional de Resíduos Sólidos, de acordo com o art. $2^{\circ}$, inc. XVI define os resíduos sólidos como:

\begin{abstract}
Material, substância, objeto ou bem descartado resultante de atividades humanas em sociedade, a cuja destinação final se procede, se propõe proceder ou se está obrigado a proceder, nos estados sólido ou semissólido, bem como gases contidos em recipientes e líquidos cujas particularidades tornem inviável o seu lançamento na rede pública de esgotos ou em corpos d'água, ou exijam para isso soluções técnicas ou economicamente inviáveis em face da melhor tecnologia disponível.
\end{abstract}

Os destaques da Lei da Política Nacional de Resíduos Sólidos são: gestão integrada dos resíduos sólidos, responsabilidade compartilhada, logística reversa e inclusão social dos catadores.

A gestão integrada de resíduos sólidos, segundo a Resolução CONAMA - Conselho Nacional do Meio Ambiente - no 448, de 18 de janeiro de 2012 é o "conjunto de ações voltadas para a busca de soluções para os resíduos sólidos, de forma a considerar as dimensões política, econômica, ambiental, cultural e social, com controle social e sob a premissa do desenvolvimento sustentável" (Art. $1^{\circ}, \S 12^{\circ}$ ). Essa gestão não se aplica somente aos resíduos sólidos da construção civil e abrange as esferas políticas municipais, estaduais e federais.

Dessa forma, o governo, junto com o apoio do município e da sociedade, luta para reduzir a geração de lixos e o desperdício, buscando reciclar e reutilizar materiais quando permissível e, 
além disso, minimizar o volume de massa de resíduos destinados a aterros e lixões a céu aberto, propondo um descarte adequado aos rejeitos. Engloba também a redução da poluição e dos danos ambientais.

Quanto à logística reversa, de forma geral, inclui o recolhimento de embalagens e produtos após o consumo, como pilhas, baterias, lâmpadas e eletroeletrônicos, assegurando assim também sua reciclagem. Essa política envolve principalmente as empresas geradoras desses objetos.

Um dos itens da PNRS é a proibição de catadores nos lixões, dessa forma a integração deles no ciclo de reciclagem se faz fundamental para garantir além da inclusão social, a criação de renda.

\section{OBJETIVO}

O objetivo desta pesquisa é desenvolver um diagnóstico quantitativo da implantação do Plano de Gestão Integrada dos Resíduos Sólidos na região do município de Araçatuba, Estado de São Paulo.

\section{METODOLOGIA}

A metodologia consiste na revisão bibliográfica de livros, artigos, sites especializados para a formulação da base da pesquisa, após houve coleta de dados nos municípios da região de Araçatuba a partir do Plano Municipal de Gestão Integrada de Resíduos Sólidos. Outro aspecto a ser considerado é se realmente as cidades têm a lei de resíduos sólidos aprovada pela câmara municipal.

Resumidamente, serão classificados três tipos de cidades:

Tipo I: aquelas que possuem o Plano aprovado;

Tipo II: aquelas que não possuem o Plano aprovado;

Tipo III: aquelas que o Plano está em elaboração.

A partir desse contato com as prefeituras e outros órgãos públicos, os dados coletados servirão de base para a elaboração de gráficos e tabelas das análises. Outro item relevante a ser abordado é a quantidade de habitantes.

\section{JUSTIFICATIVA}

A geração total de resíduos sólidos no Brasil em 2014 foi de aproximadamente 78,6 milhões de toneladas, $2,9 \%$ a mais que em 2013 , índice superior à taxa de crescimento populacional no país no período, que foi de $0,9 \%$ (ABRELP, 2015).

Ainda de acordo com a ABRELP, no que se refere à coleta, houve um aumento de 3,20\% no total de resíduos sólidos coletados em 2014 relativamente a 2013. A comparação deste índice com o crescimento da geração de resíduos sólidos mostra uma discreta evolução na cobertura dos serviços de coleta de resíduos sólidos, o qual atingiu um total de 71.260 .045 toneladas coletadas no ano. 
A comparação entre a quantidade de resíduos sólidos gerados e os coletados em 2014 mostra que o país contou com um índice de cobertura de coleta de $90,6 \%$, levando à constatação de que pouco mais de 07 milhões de toneladas deixaram de ser coletadas no país neste ano e, consequentemente, tiveram destino impróprio.

O descarte inadequado de resíduos ocasiona uma série de problemas ambientais visíveis e invisíveis, como colocar em risco a saúde da população local, contaminação dos rios e outros fatores que agridem o meio ambiente. Em razão disso, foi elaborada uma lei para criar um Plano de Gerenciamento de Resíduos Sólidos, a Lei no 12.305/10, na qual permite que os municípios brasileiros façam suas partes juntos com as entidades públicas e privadas.

O modo como os lixos e resíduos vão ser eliminados é de extrema importância à população e ao meio ambiente. Um simples ato inocente de descarte impróprio de um material poluente pode comprometer a fauna, flora, rios e ecossistemas. Hoje um dos principais focos da conscientização social são o desenvolvimento ambiental e a sustentabilidade, na qual sempre foram importantes temas da Conferência das Nações Unidas sobre Meio Ambiente e Desenvolvimento.

O estudo da implantação do Plano Municipal de Gestão Integrada de Resíduos Sólidos permite verificar como está sendo feita essa eliminação dos resíduos sólidos e, simultaneamente, a preservação das questões ambientais, sociais e sustentáveis garantir um e futuro melhor às gerações.

\section{RESULTADOS}

A pesquisa envolve os 43 municípios existentes na região de Araçatuba, a fim de obter o maior número de resultados possíveis para aprimorar cada vez mais o ojetivo da pesquisa.

Do total de 43 municípios analisados, apenas 30 atendem a lei no 12.305/10 - Política Nacional de Resíduos Sólidos - PNRS, contendo o plano aprovado pela câmara municipal de seus respectivos municípios, 06 estão com o PNRS em elaboração, 05 não possuem o Plano e 02 não responderam (gráfico 1.1).

Sendo assim, as cidades são classificadas em três categorias:

Tipo I: aquelas que possuem o Plano aprovado: Andradina, Araçatuba, Avanhandava, Barbosa, Bento de Abreu, Bilac, Birigui, Braúna, Buritama, Castilho, Gabriel Monteiro, Gastão Vidigal, Glicério, Guaraçaí, Guararapes, Guzôlandia, Ilha Solteira, Lavínia, Luiziânia, Murutinga do Sul, Nova Castilho, Nova Independência, Penápolis, Piacatu, Rubiácea, Santo Antônio do Aracanguá, Santópolis do Aguapeí, Sud Menucci, Turiuba e Valparaíso.

Tipo II: aquelas que não possuem o Plano aprovado: Alto Alegre, Auriflama, Coroados, Itapura e Nova Luzitânia.

Tipo III: aquelas que estão com o Plano em elaboração: Brejo Alegre, General Salgado, Lourdes, Mirandópolis, Pereira Barreto e Suzanápolis. 


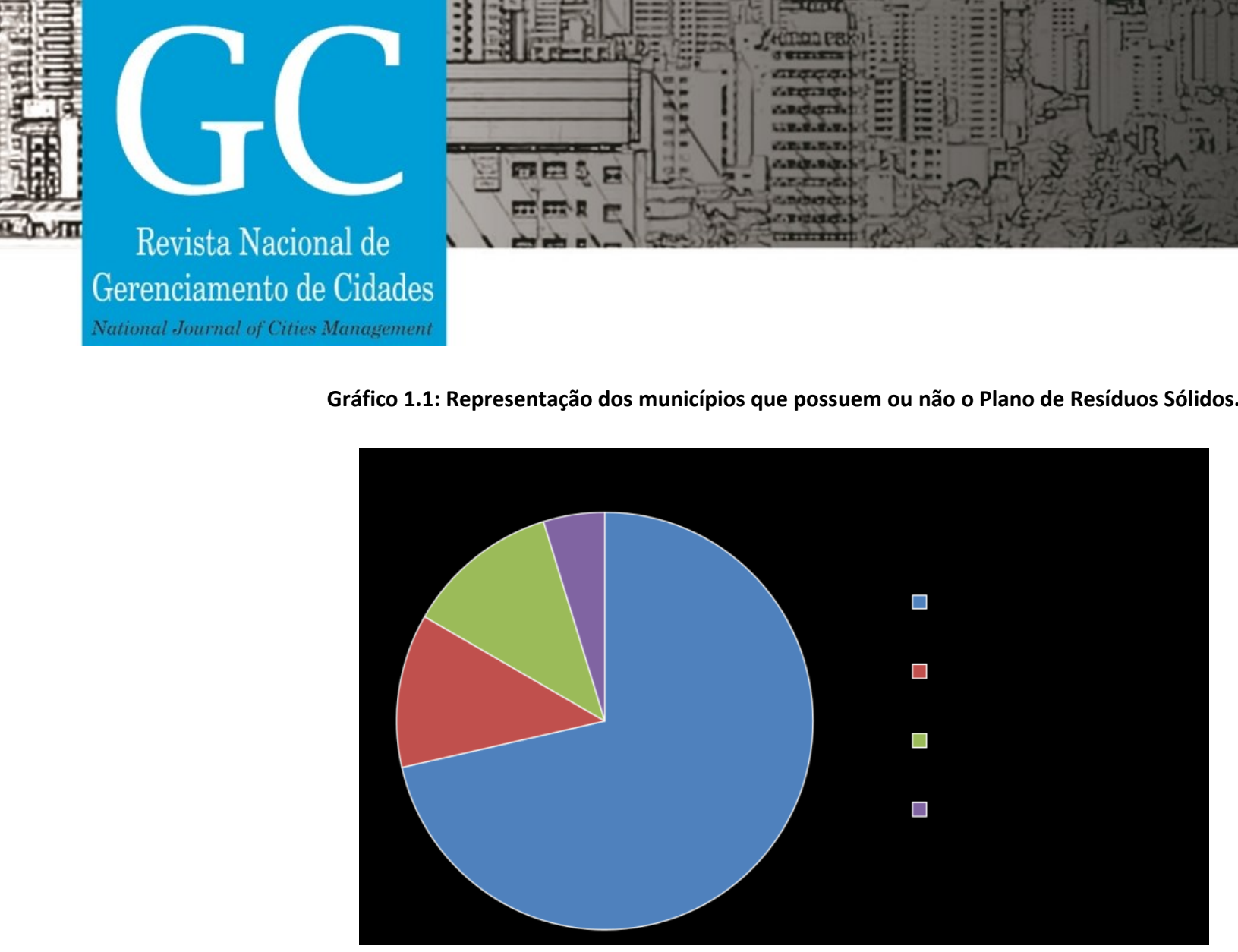

Fonte: TERNEIRO, 2016.

Após entrar em contato com as cidades e verificar quantos possuem ou não o Plano, foi realizado uma análise em relação a população do município pelo Plano. Do total dos municípios que possuem o plano, apenas 20 municípios têm a população entre 0001 a 10.000 habitantes; 3 têm a população entre 10.001 a 20.000 habitantes; 3 têm a população entre 20.001 a 50.000 habitantes e 4 têm acima de 50.000 habitantes (gráfico 1.2).

Gráfico 1.2: Representação dos municípios que possuem o Plano através da análise habitantes X Plano.

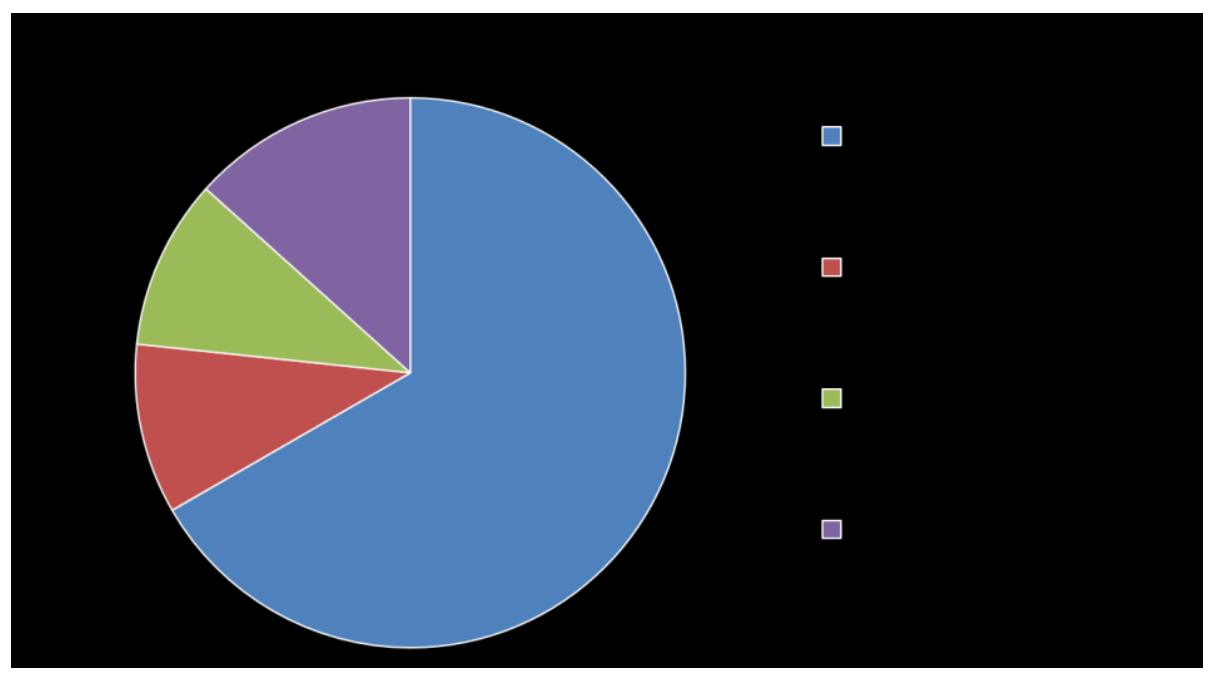

Fonte: TERNEIRO, 2016. 
Já nos municípios que não possuem o Plano foi possível verificar que: 7 municípios têm a população entre 0001 a 10.000 habitantes; 2 têm a população entre 10.001 a 20.000 habitantes; 2 têm a população entre 20.001 a 50.000 habitantes, nenhum município tem a população acima de 50.000 habitantes e apenas 2 não responderam (gráfico 1.3).

Gráfico 1.3: Representação dos municípios que não possuem o Plano através da análise habitantes X Plano.

\section{PLANO DE RESÍDUOS SÓLIDOS (HABITANTES X PLANO)}
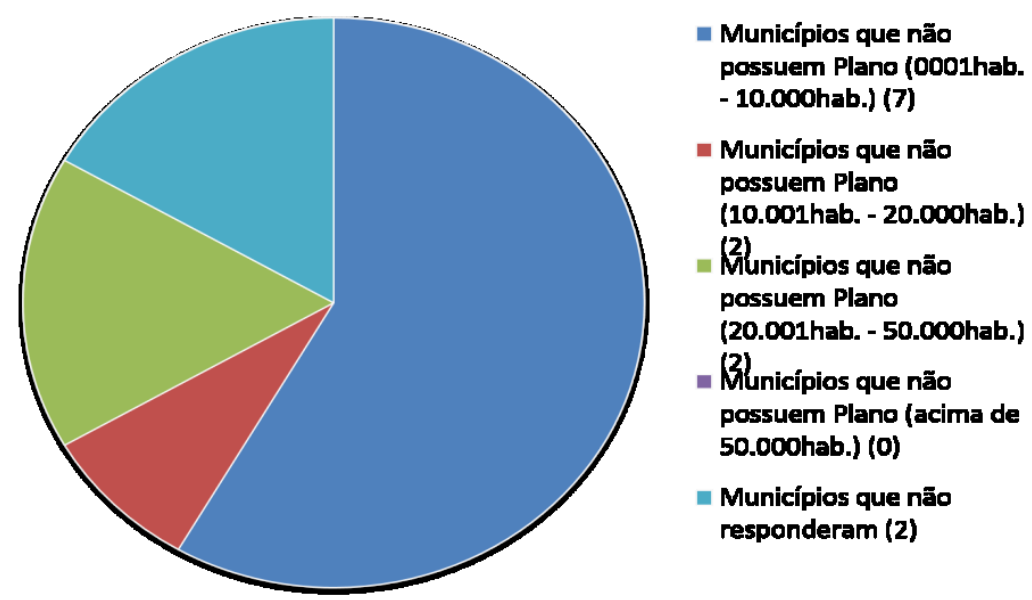

Fonte: TERNEIRO, 2016.

\section{CONCLUSÃO}

O Levantamento da pesquisa mostra que apesar de diversas políticas governamentais referentes ao assunto, alguns municípios ainda não colocam em prática as diretrizes apontadas. Além de mostrar os malefícios que eles estão trazendo ao meio ambiente com o descarte dos resíduos sólidos urbanos em lugares inadequados, como os lixões.

Com isso, não somente a população ganha benefícios sociais e ambientais, mas sim o país inteiro, colocando-o em patamar de igualdade com países desenvolvidos. O lixo e os danos ambientais que podem ser causados torna-se um problema de todos e a solução parte de cada um.

Divulgando publicamente essa pesquisa, irá alertar a sociedade e os órgãos públicos dos riscos que eles estarão sofrendo quando agridem aspectos ambientais, de forma irracional ou até mesmo racional. Assuntos voltados ao meio ambiente não devem ficar apenas no papel, mas serem colocados em práticas de forma rigorosa para beneficiar todas as pessoas. 


\section{AGRADECIMENTO}

Agradecemos, primeiramente, a Deus pela força e energia para realizar essa pesquisa, ao nosso orientador e professor Rafael Marçal por nos orientar e transmitir o seu conhecimento, a coordenadora e professora Gislaine Bianchi por nos incentivar e aos familiares por acreditar em nós.

\section{REFERÊNCIAS}

Brasil. Lei $\mathrm{n}$ - 12.305, de 02 de agosto de 2010. Institui a Política Nacional de Resíduos Sólidos; altera a Lei $\mathrm{n}$ 9.605, de 12 de fevereiro de 1998; e dá outras providências. Diário oficial da União. Brasília, DF.

CONAMA. Resolução no 448, de 18 de janeiro de 2012. Disponível em: < http://a3p.jbrj.gov.br/pdf/Resol448.pdf > Acesso em: 07 de março de 2016.

Info Escola. Definição de Resíduos Sólidos. Disponível em: < http://www.infoescola.com/ecologia/definicao-deresiduos-solidos/ > Acesso em 08 de março de 2016.

MENSOR, M.T.C. et. al. Governo do Estado de São Paulo e Secretaria do Meio Ambiente. Resíduos Sólidos. Disponível em < http://www.ambiente.sp.gov.br/wp-content/uploads/publicacoes/sma/6-ResiduosSolidos.pdf > Acesso em: 08 de março de 2016.

Ministério do Meio Ambiente. Política Nacional de Resíduos Sólidos. Disponível em:< http://www.mma.gov.br/pol\%C3\%ADtica-de-res\%C3\%ADduos-s\%C3\%B3lidos> Acesso em: 07 de março de 2016.

Ministério do Meio Ambiente. Resíduos Sólidos. Disponível em: < http://www.mma.gov.br/cidadessustentaveis/residuos-solidos > Acesso em: 07 de março de 2016.

Norma Brasileira. Resíduos sólidos - Classificação. Disponível em: < http://www.videverde.com.br/docs/NBR-n10004-2004.pdf > Acesso em: 08 de março de 2016. 